\title{
Desafios e limitações do enfermeiro inerentes à incorporação de novas tecnologias
}

\section{Nurses' challenges and limitations inherent in the incorporation of new technologies}

\author{
Luísa Perissé' • Bárbara Taís Perissé ${ }^{\bullet}$ Caroliny dos Santos Guimarães da Fonseca ${ }^{3}$ \\ Carlos Eduardo Peres Sampaio ${ }^{4}$
}

Há centenas de anos, o enfermeiro é conhecido por ser mais ligado ao cuidado de enfermos que qualquer outra classe profissional e, apesar de ser caracterizada como uma profissão "prática", sua atuação depende inteiramente do conhecimento técnico científico e aprimoramento profissional constante.

Nas últimas décadas, tem-se observado o expressivo avanço de tecnologias, o que impacta de diferentes formas a sociedade, meio ambiente e campo social e econômico. O trabalhador vivenciou a necessidade de adaptar-se a novas situações em seu ambiente de trabalho e a atuação do enfermeiro, especificamente, sofreu intensas e significativas mudanças. $O$ advento das novas tecnologias em saúde, como tudo aquilo que é novo, trouxe também medo e angústia, sentimentos que, na prática de enfermagem, podem repercutir em situações de afastamento do cliente( ${ }^{(1)}$.

A incorporação de novas tecnologias criou necessidades que vão muito além de aprender a manusear um novo equipamento. Torna-se imprescindível entender seu conceito, para que seja possível avaliar sua necessidade de utilização, identificar o mau funcionamento, proceder com ajustes e regulagem, bem como empregar técnicas de higienização adequadas ${ }^{(2)}$. Para tal, é necessário que o enfermeiro possua disponibilidade para aprender as novas técnicas e utilizá-las a seu favor no cuidado(l).

Confrontados com tais demandas, esses profissionais podem apresentar respostas sintetizadas em duas categorias: aqueles que não querem dominar a tecnologia e os que superam seus receios e se interessam em adquirir novos conhecimentos. Para estes, o principal processo é o enfrentamento do natural estranhamento concomitante à utilização de meios para adquirir o entendimento necessário à utilização dos novos equipamentos e métodos ${ }^{(1)}$. Para o primeiro grupo, há de se considerar que o medo e a consequente resistência aos novos aparatos podem influenciar negativamente na assistência, no sentido de privar o paciente de instrumentos e mecanismos que poderiam ser essenciais ao cuidado e recuperação do paciente.

Além do desafio de enfrentar seus receios para lidar com o novo e desconhecido, as equipes de enfermagem precisam cuidar-se de outros fatores importantíssimos: o fato de o desenvolvimento tecnológico estar atrelado, muitas vezes, a organizações de trabalho e produção que impulsionam, enfaticamente, a atividade para a melhoria da relação custo-eficiência-benefício, tornando as relações enfermeiro-paciente pouco humanas ${ }^{(2)}$ e também ao fato de que o uso irracional de tecnologias pode ser mais prejudicial do que benéfico. Em situações como o parto ${ }^{(3)}$, e muitas outras, quando não se priorizam as tecnologias apropriadas e estritamente necessárias, pode-se ferir o princípio de não maleficência e causar transtornos irreversíveis ao paciente.

Considerando as dificuldades apresentadas e que uma das atribuições do enfermeiro é garantir uma assistência segura e de qualidade, torna-se imperioso que esse profissional esteja apto à adoção de técnicas que permitam não só o uso correto de tecnologias, mas também a integração das mesmas com o cuidado holístico e humanizado.

\footnotetext{
'Especialista em Enfermagem do Trabalho pela Universidade Federal do Rio de Janeiro e Clínica Médica e Cirúrgica nos Moldes de Residência pela Universidade Federal do Estado do Rio de Janeiro e em Neonatologia pela Universidade Veiga de Almeida.

${ }^{2}$ Especialista em Enfermagem do Trabalho pela Universidade Federal do Rio de Janeiro e em Neonatologia pela Universidade Veiga de Almeida.

${ }^{3}$ Mestranda em Bioética e Ética Médica na Universidad Européa Del Atlántico, Catabria - Espanha. Especialista em Auditoria em Sistemas de Saúde, Gestão em Enfermagem e Urgência e Emergência.

${ }^{4}$ Mestre e Doutor em Bioquímica Médica pela Universidade Federal do Rio de Janeiro. Professor Associado da Universidade do Estado do Rio de janeiro. Professor Titular da Universidade Veiga de Almeida.
} 
O enfermeiro, profissional que compreende em demasia as necessidades de cuidados do paciente, é indispensável na participação no planejamento estratégico de avaliação, seleção, aquisição e aplicação clínica de novas tecnologias, no sentido de assegurar 0 atendimento ideal das necessidades terapêuticas e assistenciais ${ }^{(2)}$.

Nesse sentido, além de resgatar a autonomia do enfermeiro, é primordial garantir que a tecnologia seja utilizada em favor da assistência. Para tal, promover conscientização das equipes acerca da importância de desempenharem com fluidez e interatividade uma assistência humanizada, resolutiva e de qualidade e reduzir o estresse das mesmas frente às novidades tecnológicas torna-se indispensável na rotina dos setores. E, para além disso, torna-se fundamental promover permanentes capacitações técnicas, supervisão das atividades desempenhadas e dar acompanhamento com suporte necessário diante de demandas verificadas. Tais medidas asseguram que o avanço tecnológico sirva como propulsor do aperfeiçoamento da relação custo-eficiência-benefício do trabalho assistencial implementado(2,4).

Os profissionais devem cientificar-se que garantir o bom funcionamento do setor requer uma desenvoltura diferenciada no sentido de adaptar-se ao uso de novos dispositivos e ao aperfeiçoamento das técnicas de cuidados envolvidas, no intuito de aperfeiçoar e humanizar a assistência.

Ser enfermeiro implica dedicar-se ao cuidado direto concomitantemente ao aprimoramento profissional, lidar com enfermidades as mais variadas possíveis e tratando a todas com a mesma diligência, utilizar conhecimentos técnico-científicos na prática do cuidado e a tecnologia a favor da assistência. Tudo isso pautado pela certeza de que cada indivíduo é único, que a clínica, diversas vezes, se mostrará soberana e que o cuidado humanizado é tão antigo quanto essencial. 


\section{REFERÊNCIAS}

I. Bezerra CMB, Silva KKM,Aquino,ASF, Martino MMF. Instrumentos verificadores de estresse e da Síndrome de Burnout: Revisão Integrativa. Ver Enferm Atual. 2016; 79:64-9;

2. Arone EM, Cunha ICKO. Tecnologia e humanização: desafios gerenciados pelo enfermeiro em prol da integralidade da assistência. Rev. bras. enferm. 2007; 60(6): 721-3;
3. Diniz CSG. Humanização da assistência ao parto no Brasil: os muitos sentidos de um movimento. Ciênc. saúde coletiva. 2005; 10(3):627-37;

4. Sangiovo S, Andrade A, Arboit EL, Cosentino SF. Potencialidades e fragilidades de uma equipe de enfermagem em Centro Cirúrgico. Revista Espaço Ciência \& Saúde. 2015; 3:I-14. 